\title{
Microalgal Bioassays as a Test of Pesticide Photodegradation Efficiency in Water
}

\author{
C. Rioboo, 1 D. Franqueira,1 M. L. Canle,2 C. Herrero, 1 A. Cid $1{ }^{1}$
}

Bulletin of Environmental Contamination and Toxicology, August 2001, Volume 67, Issue 2, pp 233-238

Received: 10 January 2001/Accepted: 12 April 2001

DOI: $10.1007 / \mathrm{s} 00128-001-0115-x$

As much as ca. $99.7 \%$ of the applied load of pesticides is dispersed in the environment, not reaching the target pests. In this way, pesticide enter into aquatic ecosystems from agricultural runoff or leaching and. as a consequence, have become some of the most frequently occurring organic pollutants in aquatic ecosystems (Pimentel 1995; Ibanez et al. 1996).

Photodegradation is one of the processes that pesticides may undergo once dispersed in the environment. It requires an adequate overlapping between the emission spectrum of the light source and the absorption spectrum of the compound to be degraded. When such condition is fulfilled, molecules undergo light absorption, being promoted to an excited electronic state, from where they can relax via different pholophysical and/or photochemical processes. Considering the typical absorption spectra shown by common pesticides, the small portion of UVA and the UVB components of sunlight reaching the Earth's surface (Murov et al. 1993) are adequate to initiate such photodegradation processes. UVA light is widely used nowadays as basis of advanced water-disinfection methods (Sommer et al. 1997), with the subsequent photo-initiated reactions of the organic pollutants present in water (Moctczuma ct al. 1999).

Unicellular algae are in the basis of the energy flow in the aquatic trophic chain. Their use in toxicity bioassays show great advantages: microalgae are very sensitive to xenobiotics, easy of handling and have a short life cycle (Hörnström 1990). In this work, two freshwater rnicroalgal species, Chlamydomonas moewusii and Chlorella vulgaris, were respectively used to assess the efficiency of photodegradation of the two commonly used herbicide, paraquat and isoproturon. Paraquat (1.1'-dimethyl-4,4'-bipyridinium dichloride) is a non-selective aquatic and terrestrial total contact quick-acting herbicide, freely soluble in water in the form of its dichloride

\footnotetext{
${ }^{1}$ A1. Laboratory of Microbiology, Faculty of Sciences, University of A Coruña, A Zapateira s/n, A Coruña, E-15071 Spain, ES

A2. Laboratory of Physical Chemistry, Faculty of Sciences, University of A Coruña, A Zapateira s/n, A Coruña, E-15071 Spain, ES
} 
salt (Meister and Sine 1998). Isoproturon (3-(4-isopropylphphenyl)-1,1-dimethylurea) is a selective systemic herbicide, relatively soluble in water (Meister and Sine 1998).

\section{MATERIAL AND METHODS}

The biotoxicity of the pesticides were determined as a function of the evolution of growth and photosynthetic pigment content of the assayed microalgae, along the 96 hours of treatment with pure pesticides as well as with the products resulting from their photodegradation, carried out by excitation with laser light of $248 \mathrm{~nm}$, a laser wavelength readily available.

Paraquat and isoproturon were Riedel de Häen-Pestanal standards for environmental analysis. HPLC and GC tests showed the purity was in both cases higher than $97 \%$. The water used to prepare the solutions was obtained from a Millipore-Milli $Q$ system. In order to have a proper control of the irradiation conditions, the photolysis of both herbicides was performed at $248 \mathrm{~nm}$ excimer laser. In this way, $1.18 \mathrm{mM}$ paraquat solutions were irradiated with 100 laser pulses (120 mJ/pulse output of the laser), while $0.1 \mathrm{mM}$ isoproturon solutions were irradiated with 100 laser pulses (104 mJ/pulse). All solutions were deaerated by flow of Ar during the photolysis, that was carried out in Suprasil quartz cells at ca. $293 \pm 2 \mathrm{~K}$.

Microalgal cultures were carried out as described in Franqueira et at. (1999). Pure paraquat concentrations assayed were 0.30 and $0.60 \mu \mathrm{M}$. Initial density for C. moewusii cultures was $1 \times 10^{5}$ cells $\cdot \mathrm{mL}^{-1}$. Pure isoproturon concentrations assayed were 0.125 and $0.5 \mu \mathrm{M}$. Initial density for C. vulgaris cultures was $9 \times 10^{6}$ cells $\cdot \mathrm{mL}^{-1}$ In all experiments, control cultures without pesticide were also included. All the reported experiments were carried out in triplicate, and the results are expressed as the average of the three replicates.

Growth of the microalgal cultures was measured by counting daily culture aliquots in a Neubauer hemocytometer, and growth rates were expressed in day $^{-1}$. The most common parameter used in toxicity assays is the $\mathrm{EC}_{50}$ i.e., the concentration of the tested substance that decreases the growth by $50 \%$. In order to obtain a confidence interval for the $\mathrm{EC}_{50}$ value, probit analysis of the growth data was carried out using the SPSS-PC+ software (SPSS Inc.)

The photosynthetic pigments of C. moewusii were determined after 96 hours of culture, by spectrophotometrical measurements in $90 \%$ acetone extracts, using the equations of Jeffrey and Humphrey (1975) for chlorophylls, and Strickland and Parsons (1972) for total carotenoids. C. vulgaris pigments were extracted with pure methanol and the equations used were those described in Lichtenthaler (1987).

Data were statistically analyzed by an overall one-way analysis of variance (ANOVA) $(p<0.05)$. 
Table 1. Growth rate $\left(\right.$ day $\left.^{-1}\right)$ and photosynthetic pigments content $\left(\mathrm{pg}\right.$ cell $\left.^{-1}\right)$ of C. moewusii cultures exposed to paraquat.

\begin{tabular}{lccc} 
& Control & $0.3 \mathrm{mM}$ & $0.6 \mathrm{mM}$ \\
\hline Growth rate & $0.77 \pm 0.01$ & $0.36 \pm 0.01$ & $-0.22 \pm 0.02$ \\
Chlorophyll a & $3.91 \pm 0.32$ & $2.61 \pm 0.17$ & $2.91 \pm 0.25$ \\
Chlorophyll b & $0.97 \pm 0.08$ & $0.6 \pm 0.37$ & $1.29 \pm 0.08$ \\
Carotenoids & $1.16 \pm 0.06$ & $0.9 \pm 0.07$ & $0.77 \pm 0.05$ \\
\hline $\mathrm{n}=3$ & & &
\end{tabular}

\section{RESULTS AND DISCUSSION}

The growth of C. moewusii was reduced to ca. $50 \%$ by a paraquat concentration of $0.30 \mu \mathrm{M}$ $\left(E C_{50}=0.28 \mu \mathrm{M}\right.$ ), while a concentration of $0.60 \mu \mathrm{M}$ inhibited the growth ofthis microalga (Table 1). In studies with other species, as $C$. reinhardtii, the growth ofthe microalgal cultures was inhibited with lower concentrations of paraquat (0.30 11M) (Bray et al. 1993).

Another parameter commonly used in ecotoxicological studies is the response of photosynthetic pigments to the presence of pollutants in the environment (Ibrahim 1990; Cid et al. 1995; Franqueira et al. 1999). In general, the presence of paraquat leads to a decrease in the cellular content of chlorophyll-a and total carotenoids relative to the control cultures (Table 1). The low content of pigment may result from oxidation of chlorophyll-a due to the oxidative stress caused to the Chlamydomonas cells by the high levels of oxidant radicals formed by intermediacy of paraquat. In this connection, paraquat has been reported to cause a decline in photosynthetic electron transport, apparently due to competition for and diminution of the NADPH pool, disruption of thylacoid structure and oxidative breakdown of chlorophyll (Kirtikara and Talbot 1996).

As stated, photodegradation is one of the factors controlling the fate of pesticides and other chemicals in the environment (Parlar et al. 1990). Photolysis is also involved in the photoactivation and photocontrolled release of a number of bioactive molecules, including some insecticides, fungicides and herbicides (Climent and Miranda 1996). Paraquat has been shown to photo degrade to different intermediate products, such as monoquat, monopiridone, picolinic acid and succinic acid (Kearney et al. 1985; Moctezuma et al. 1999).

The concentrations of photodegraded solutions referred below are based on the initial concentration of pure herbicide prior to photodegradation. A photo degraded solution of paraquat ([Paraquat $]_{0}=0.30 \mu M$ ) was assayed to study the effect of photodegradation of this herbicide on micro algae. The photodegraded solution led to a slight increase of the growth and pigment content of C. moewusii relativeto the control cultures (Table 3), which can be attributed to an effective mineralization (photodegradation) of paraquat by $248 \mathrm{~nm}$ light.

On the other hand, the growth of C. vulgaris was reduced to ca. $50 \%$ by a concentration of isoproturon of $0.125 \mu \mathrm{M}\left(\mathrm{EC}_{50}=0.15 \mu \mathrm{M}\right)$, while a $0.5 \mu \mathrm{M}$ concentration inhibited the growth of this microalga (Table 2). Other studies testing the herbicide paraquat with $\mathrm{C}$. vulgaris, have 
showed higher values of the $E_{50}$ for growth after 96 hours of treatment $(0.54 \mu M)$ (Traunspurger et al. 1996). These results indicate that isoproturon is more toxic than the paraquat. Since the toxicity of different pollutants are close related with the species of the microorganism test, it seems that Chlamydomonas is more sensitive than Chiarella.

Both isoproturon concentrations assayed led to a decrease in the pigment content (Table 2). The content of chlorophyll-a for $0.50 \mu \mathrm{M}$ isoproturon is higher than that observed for $0.125 \mu \mathrm{M}$, possibly due to a tolerance mechanism (Kirtikara and Talbot 1996).

Table 2. Growth rate $\left(\right.$ day $\left.^{-1}\right)$ and photosynthetic pigments content $(\mathrm{pg}$ cell-1) of C. vulgaris cultures exposed to isoproturon.

\begin{tabular}{lccc} 
& Control & $0.125 \mathrm{mM}$ & $0.5 \mathrm{mM}$ \\
\hline Growth rate & $0.97 \pm 0.03$ & $0.66 \pm 0.03$ & $0.19 \pm 0.03$ \\
Chlorophyll a & $0.78 \pm 0.07$ & $0.11 \pm 0.09$ & $0.34 \pm 0.03$ \\
Chlorophyll b & $0.40 \pm 0.02$ & $0.03 \pm 0.00$ & $0.03 \pm 0.01$ \\
Carotenoids & $0.20 \pm 0.07$ & $0.03 \pm 0.01$ & $0.03 \pm 0.01$ \\
\hline $\mathrm{n}=3$ & &
\end{tabular}

The photodegradation of isoproturon is thought to take place leading to substituted anilines and ureas as the main products. Photo degraded isoproturon ([Isoproturon] $]_{0}=0.30 \mu \mathrm{M}$ ) led to a decrease of the growth of C. vulgaris cells, relative to the control cultures (Table 3). However, the decrease of growth observed with photo degraded isoproturon was lower than that for the case of the pure herbicide. In what regards the pigments content, photodegraded isoproturon led to an increase after 96 hours of treatment (Table 3). This fact can be attributed to an increase in the cell volume of $\mathrm{C}$. vulgaris cells, that has been observed under the optic microscope.

Table 3. Percent variation, relative to control cultures, of growth and photosynthetic pigments, for cultures of $C$. moewusii exposed to photodegraded paraquat and C. vulgaris exposed to photodegraded isoproturon.

\begin{tabular}{lcccc} 
& Growth rate & Chlorophyll a & Chlorophyli b & Carotenoids \\
\hline Paraquat $0.30 \mu M$ & $114 \pm 2$ & $113 \pm 6$ & $112 \pm 4$ & $113 \pm 7$ \\
Isoproturon $0.15 \mu M$ & $70 \pm 4$ & $181 \pm 3$ & $203 \pm 14$ & $161 \pm 7$ \\
\hline
\end{tabular}

The results presented here show that the use of UV $(248 \mathrm{~nm})$ light for photodegradation of herbicides can be effective (although the photodegradation process must be optimized). The degree of effectiveness of the photodegradation process has been shown to be different for paraquat and isoproturon, using as biotoxicity test the evolution of growth and the photosynthetic pigment content of C. moewusii and C. vulgaris.

\section{Acknowledgements.}


This work was carried out with the financial support of the Xunta de Galicia (XUGA 10307 A98). D.F. acknowledges a F.P.U. fellowship from the Spanish Ministerio de Educacion y Cultura. C.R. acknowledges a PhD fellowship from the Xunta de Galicia.

\section{REFERENCES}

Bray DF, Bagu JR, Nakamura K (1993) Ultrastructure of Chlamydomonas reinhardtii following exposure to paraquat: comparison of wild type and a paraquat-resistant mutant. Canadian $\mathrm{J}$ Bot 71: $174-182$

Cid A, Herrero C, Torres E, Abalde J (1995) Copper toxicity on the marine microalga Phaeodactylum tricornutum: effects on photosynthesis and related parameters. Aquat Toxicol 31: $165-174$

Climent MJ, Miranda MA (1996) Gas chromatographic-mass spectrometric study of photodegradation of carbamate pesticides. J Chromatogr A 738: 225-231

Franqueira D, Cid A, Torres E, Orosa M, Herrero C (1999) A comparison of the relative sensitivity of structural and functional cellular responses in the alga Chlamydomonas eugametos exposed to the herbicide paraquat. Arch Environ Contam Toxicol 36: 264-269

Hömström E (1990) Toxicity test with algae. A discussion on the batch method. Ecotoxicol Environ Safety 20: 343-353

Ibáñez M, Pico Y, Manes J (1996) Influence of organic matter and surfactants on solid-phase extraction of diquat, paraquat and difenzoquat from waters. J Chromatogr A 727: 245-252

Ibrahim EA (1990) The influence of the herbicide paraquat "gramoxon» on growth and metabolic activity of three chlorophytes. Water Air Soil Pollut 51: 89-93

Jeffrey SW, Humphrey GF (1975) New spectrophotometric equations for determining chlorophylls $\mathrm{a}, \mathrm{b}, \mathrm{c}_{1}$ and $\mathrm{c}_{2}$ in higher plants, algae and natural phytoplankton. Biochem Physiol Pflanz 167: 191-194

Kearney PC, Ruth JM, Zeng Q, Mazzochi P (1985) UV -Ozonation of Paraquat. J Agric Food Chern 33: 953-957

Kirtikara K, Talbot D (1996) Alteration in protein accumulation, gene expression and ascorbateglutathione pathway in tomato (Lycopersicon esculntum) under paraquat and ozone stress. J Plant Physiol 148: 752-760

Lichtenhaler HK (1987) Chlorophylls and Carotenoids: Pigments of Photosynthetic Biomembranes. Methods in Enzymology 148: 350-382 
Meister RT, Sine C (1998) Farm Chemicals Handbook 1998. Meister Publishing Co., Willoughby (Ohio, U.S.A.)

Moctezuma E, Leyba E, Monreal E, Villega N, Infante D (1999) Photocatalytic degradation ofthe herbicide paraquat. Chemosphere 39: 511-517

Murov SL, Carmichael I, Hug GL (1993) Handbook of Photochemistry. $2^{\text {nd }}$ edition. Marcell Dekker, Inc., New York

Padar H, Hutson DH, Roberts TR (1990) Environmental fate of pesticides. Wiley New York

Pimentel D (1995) Amounts of pesticides reaching target pests: environmental impacts and ethics. J Agric Environ Ethics 8: 17-29

Sommer R, Cabaj A, Pribil W, Haider T (1997) Influence of lamp intensity and water transmittance on the UV disinfection of water. Wat Sci Tech 35: 113-118

Strickland JDH, Parsons TR (1972) A Practical Handbook of Seawater Analysis (ed. JC Stevenson, L W Billingsley, RH Wigmore). Fisheries Research Board of Canada, Ottawa

Traunspurger W, Shaefer H, Remde A (1996) Comparative investigation on the effect of a herbicide on aquatic organisms in single species tests and aquatic microcosms. Chemosphere 33: $1129-1142$ 